\title{
$O$ aspecto do auxiliar em debate
}

\author{
The aspect of the auxiliar in debate
}

\author{
Ana Paula Scher \\ Universidade de São Paulo - USP
}

\begin{abstract}
Bertinetto (2001) points out that in spite of the great amount of research and papers developed on the nature of aspectual and temporal relations in natural languages, the lack of consensus on some very basic notions related to this topic is still remarkable. The paper by Wachowicz, presented at the annual Encontro do GT em Teoria da Gramática da ANPOLL, in Ouro Preto, from $1^{\text {st }}$ to $2^{\text {nd }}$ of December, 2005 and, later, published in volume 14, number 2 of this magazine, constitutes an interesting attempt to clarify some questions on a very underexplored topic, namely, the aspectual reading in sentences with verbal periphrases in which the first verb is an auxiliary. This paper discusses Wachowicz's proposal, raising some questions and making some observations on it. It aims at contributing to the research being developed, with the reflections by someone who is not directly involved in it.
\end{abstract}

\section{Keywords}

Aspect, Auxiliary, Verbal periphrases

\section{Resumo}

Bertinetto (2001) aponta que, apesar das inúmeras pesquisas e artigos desenvolvidos e elaborados sobre a natureza das relações aspectuais e temporais nas línguas naturais, a falta de consenso sobre algumas noções fundamentais relacionadas ao assunto ainda é notável. O artigo de Wachowicz, apresentado no Encontro do GT em Teoria da Gramática da ANPOLL, em Ouro Preto, de 1 a 2/12/2005, e 
posteriormente publicado no volume 14, número 2 desta revista, constitui uma tentativa interessante de esclarecer algumas questões sobre um tema cuja exploração ainda se mostra insuficiente, nomeadamente, a leitura aspectual em sentenças com perífrases verbais em que o primeiro verbo é um auxiliar. Neste artigo, discuto a proposta de Wachowicz, levantando algumas questões e fazendo algumas observações. Meu objetivo é contribuir para a pesquisa em desenvolvimento, com as reflexões de alguém que não está diretamente envolvido nela.

\section{Palavras-chave}

Aspecto, Auxiliar, Perífrases verbais 


\section{Introdução}

discussão sobre questões aspectuais e temporais tem sido ampla na
literatura lingüística moderna. Mesmo assim, como aponta Bertinetto
(2001), é ainda notável a falta de consenso sobre algumas noções básicas relacionadas a essas questões. Dessa forma, a pesquisa de Wachowicz, publicada no volume 14, número 2 desta revista, sobre o aspecto do auxiliar é uma tentativa interessante de esclarecer uma questão ainda pouco explorada, nomeadamente a leitura aspectual em sentenças com perífrases verbais em que o primeiro verbo da perífrase é um auxiliar.

Neste trabalho, apresento, para a proposta de Wachowicz, algumas observações que fiz e questões que levantei na mesa redonda sobre aspecto e eventos que teve lugar no Encontro do GT em Teoria da Gramática da ANPOLL, em Outro Preto, de 1 a 2 de dezembro de 2005. O trabalho se organiza em quatro seções, incluindo esta introdução. Na seção 2, apresento as linhas gerais da proposta de Wachowicz . Em seguida, na seção 3, apresento minhas observações e questões para essa proposta, para concluir o trabalho na seção 4.

\section{Wachowicz e o aspecto do auxiliar}

Partindo da pergunta "o que significa dizer que um verbo auxiliar é aspectual?", Wachowicz procura encontrar argumentos de natureza histórica e semântica para sua hipótese de que, tal como os verbos plenos, os auxiliares vir, ter e estar carregam informação aspectual dependente do léxico, da flexão verbal e de uma combinação desses elementos com o resto da sentença. Os traços de duração, homogeneidade e atelicidade, historicamente presentes nos auxiliares em questão, permitem a distribuição dos eventos denotados pelo verbo principal, pois abrem o intervalo do momento de referência $(\mathrm{R})$ dentro do qual os momentos de evento (E) podem ser distribuídos. É fácil perceber, portanto, que a análise proposta em Wachowicz depende crucialmente da assunção de o aspecto está na relação entre E e R (cf. JOHNSON, 1981). 
Dos trabalhos de Mattos e Silva (1989, 2001) e Cardoso e Pereira (2003) sobre as propriedades das perífrases, Wachowicz chama a atenção para dois pontos principais: o primeiro deles diz respeito às propriedades semânticas dos auxiliares. A autora aponta que a especificação dos traços de duração e homogeneidade da perífrase depende da especificação desses mesmos traços no auxiliar, mostrando que, mesmo as perífrases com verbos principais de accomplishment e achievement respondem ao teste dos advérbios em e por/ durante, sugerido por Vendler (1967), verificando o traço duração. O segundo ponto observado nos dois trabalhos diz respeito à gramaticalização do auxiliar, que não parece ser um processo homogêneo. Os auxiliares podem se encontrar em diferentes estágios do processo de gramaticalização e, por esse motivo, algumas formas de auxiliares podem ocorrer em sentenças sem comportamento de auxiliar. O que chama a atenção, no entanto, segundo Wachowicz, é que, tanto numa fase quanto na outra, os traços aspectuais de duração e homogeneidade se mantêm.

A participação do auxiliar no cálculo temporal e sua representação, associada à relação entre o momento de referência e o momento do evento também foram discutidos por Wachowicz. Sobre a questão temporal, a autora mostra, com base na interpretação de sentenças perifrásticas em que há variações temporais do verbo auxiliar, que a posição ocupada por esse elemento participa do cálculo temporal e aspectual da sentença. Com base nos valores aspectuais lexicais dos auxiliares - seus traços e suas especificações, em geral, codificados em VP - e em seus valores aspectuais gramaticais - perfectivo, imperfectivo, representados, estruturalmente, pelas categorias aspectuais relevantes - a autora sugere uma estrutura preliminar para a representação de sentenças perifrásticas que exibe um VP especificado com os traços relevantes do verbo principal, além de projeções aspectuais tanto para o auxiliar, quanto para o verbo principal.

Finalmente, para discutir a relação R e E, Wachowicz assume Bertinetto (1982) que diz que o momento de referência só se justifica teoricamente na representação dos tempos compostos e é denotado pelo verbo auxiliar. Esse autor também defende que, em tempos simples, o momento de referência e o momento do evento coincidem. Com base nisso e na proposta de Johnson (1981) de que a leitura aspectual depende da relação entre o momento do evento e o momento de referência, Wachowicz lista as seguintes conclusões teóricas, entre outras: 
o momento do evento é denotado pelo verbo principal das perífrases; o momento de referência é denotado pelo verbo auxiliar; o aspecto deriva de uma relação de inclusão entre R e E, enquanto implicações temporais derivam de uma relação de ordem entre $\mathrm{R}$ e $\mathrm{E}$.

\section{O debate: observações e questões}

Esta seção começa com uma observação sobre a afirmação que Wachowicz faz na seção 1 de seu trabalho, dizendo que os traços de duração e homogeneidade da perífrase dependem desses mesmos traços no auxiliar. Para fornecer evidências empíricas de sua afirmação, a autora traz os exemplos de perífrases com verbos principais de accomplishment e achievement em (1) e (2), respectivamente:

(1) a. João tem pintado/vem pintando/está pintando nossa casa durante todos esses anos.

b. João tem corrido até o parque/vem correndo até o parque/está correndo até o parque por quinze semanas.

(2) a. João tem encontrado/vem encontrando/está encontrando Maria durante todos esses anos.

b. João tem clicado/vem clicando/está clicando nosso site durante dois meses.

Nesses exemplos, segundo a autora, a duração é verificada pelo teste dos advérbios em e por/durante, de Vendler (1967), já que as sentenças são bem formadas com tais advérbios.

De fato, é surpreendente que uma sentença com verbo principal de achievement, como (2), seja bem formada com os advérbios mencionados anteriormente que, sem dúvida, precisam ter escopo sobre uma eventualidade que se realiza por um período de tempo. Nesse sentido, a proposta de Wachowicz de que o auxiliar abre o intervalo do momento de referência $(\mathrm{R})$ dentro do qual os momentos de evento (E) podem ser distribuídos dá conta da boa formação dos exemplos em (2).

Por outro lado, a boa formação das sentenças em (1) talvez possa se explicar pelo traço durativo que os verbos de accomplisment apresentam, sem que se precise lançar mão dos traços de duração e homogeneidade do auxiliar. 
As eventualidades denotadas por esses verbos não são homogêneas, é fato, mas precisam se desenvolver em um dado intervalo de tempo e não necessitariam da ação do auxiliar para abrir o momento de referência, para que os momentos de evento pudessem se distribuir. Por que as sentenças em (1) precisariam, então, do auxiliar? Em outros termos, se o auxiliar não precisa abrir o momento de referência nesses exemplos, qual é a sua função aqui? Qual seria a função do auxiliar em outras sentenças, como (3) e (4), cujos verbos principais denotam estado e atividade, respectivamente, eventualidades que carregam, sem o suporte do auxiliar, os traços de duração e homogeneidade?

(3) a. João tem amado/vem amando/está amando a Maria durante todos esses anos.

b. João tem sofrido/vem sofrendo/está sofrendo durante dois meses.

(4) a. João tem caminhado/vem caminhando/está caminhando no parque durante todos esses anos.

b. João tem lido/vem lendo/está lendo relatórios por quinze dias.

Além disso, o que justificaria a má-formação das sentenças de estado e accomplishment, respectivamente, em (5) e (6)? Porque, nesses casos, o auxiliar não foi capaz de abrir o momento de referência para que a distribuição dos momentos de evento se realizasse também.

(5) *João tem conhecido/vem conhecendo/está conhecendo a Maria durante todos esses anos.

(6) *João tem comido/vem comendo/está comendo o queijo durante todos esses dias.

Cabe aqui, finalmente, uma última observação sobre a questão dos traços da perífrase que se relaciona diretamente à representação sugerida na seção 3 do trabalho de Wachowicz. Essa observação diz respeito aos exemplos a seguir.

(7) *João tem construído a casa.

(8) *João tem comido o queijo.

(9) ?João tem lido o livro. 
As sentenças em (7) e (8) são irremediavelmente malformadas, enquanto (9), se não for, de fato, bem formada, pelo menos parece ser melhor que as primeiras. O que pode estar determinando essa diferença, se, nos três casos, o que temos são verbos de accomplisment? Por que motivo, o auxiliar em (7) e (8) não parece ser capaz de abrir o intervalo para a distribuição dos eventos de construir a casa ou de comer o queijo? O que torna a distribuição de eventos possível ou melhor em (9)?

Ameu ver, as propriedades do objeto desempenham um papel fundamental também nesse caso, exatamente da mesma maneira que em vários outros casos já discutidos na literatura. Nem a casa, nem o queijo em (7) e (8), respectivamente, podem denotar a mesma entidade em eventos diferentes. $\mathrm{O}$ sintagma nominal o livro em (9), por sua vez, pode, facilmente, denotar a mesma entidade em vários eventos de ler o livro que podem ser distribuídos em um determinado intervalo. A questão que se coloca novamente aqui é se esse intervalo precisa, realmente, ser aberto pelo auxiliar, uma vez que a eventualidade denotada pelo verbo principal em (9) é um accomplisment e, como tal, tem o traço durativo especificado para o valor (+) e talvez pudesse, por si mesmo, abrir o intervalo necessário para a distribuição dos eventos no momento de referência.

Uma discussão interessante pode decorrer da afirmação de Bertinetto (1982), assumida por Wachowicz, de que o momento de referência só se justifica na representação dos tempos compostos. No capítulo sobre as relações de tempo no verbo francês do livro Problemas de Lingüística Geral I, de Benveniste (1988), o autor fala que o tempo lingüístico é ligado ao exercício da fala, definindose e ordenando-se em função do discurso. Para ele, o centro desse tempo é o presente da instância da fala. Com base nesse e em outros autores, Fiorin (2002) apresenta uma sistematização dos tempos verbais, organizados de acordo com os momentos de enunciação (de fala), de referência e do acontecimento (do evento). Partindo do momento de enunciação, tomado como um presente implícito, e aplicando-se a ele as categorias da concomitância/não-concomitância, obtém-se, do lado da concomitância, o momento de referência presente e, do lado da não-concomitância, os momentos de referência pretérito e futuro. Adistinção entre eles se dá pela aplicação à categoria não-concomitância das categorias anterioridade/posterioridade. 
(10) Momento de Enunciação = PRESENTE IMPLÍCITO

qo

Concomitância Não-concomitância

MR PRESENTE qo
Anterioridade
Posterioridade
MR PRETÉRIO
MR FUTURO

A cada um desses momentos de referência, aplicam-se, por sua vez, as mesmas categorias de concomitância/não-concomitância e anterioridade/ posterioridade, para obterem-se os momentos de evento, a que correspondem os tempos verbais: todos eles, compostos ou não. O que se tem, então, são os seguintes diagramas, representativos dos três sistemas temporais:

(11) Momento de Referência PRESENTE

qo

Concomitância Não-concomitância

PRESENTE qo

Anterioridade Posterioridade

PRET. PERFEITO 1

FUTURO DO PRESENTE

(12) Momento de Referência PRETÉRITO

qo

Concomitância Não-concomitância

qo

qo

(perfeito)

(imperfeito)

Anterioridade Posterioridade

PRET. PERF. 2

PRET. IMPERF.

PRET. + QUE qo

PERF (perfeito) (imperfeito)

FUT. PRET. FUT. PRET.

SIMPLES COMP. 
(13) Momento de Referência FUTURO

qo

Concomitância Não-concomitância

PRESENTEDO qo

FUTURO Anterioridade Posterioridade

FUT. ANTERIOR FUTURO DO FUTURO

Se o momento de referência só se justifica na representação dos tempos compostos, sendo denotado pelo auxiliar, como se estabelecem as distinções entre os três momentos de referência, no sistema de Bertinetto, em sentenças como (14) e (15)?

(14) Acabei de chegar. Almocei com sua prima.

(15) No ano de 2004, acabei a dissertação. No dia da defesa, almocei com sua prima.

Em (14), o momento de referência de almocei com sua prima é PRESENTE e o tempo em que a sentença se encontra é o pretérito perfeito 1 (cf. FIORIN, 2002) e tem o valor de anterioridade em relação ao MR PRESENTE. Em (15), no entanto, o momento de referência de almocei com sua prima é PRETÉRITO e o tempo em que a sentença se encontra é o pretérito perfeito 2 (cf. FIORIN, 2002) e tem o valor de concomitância em relação ao MR PRETÉRITO. Se, como sugere Bertinetto (1982), a representação do momento de referência coincide com a do momento do evento nos tempos simples, como será possível explicar o valor distinto que cada um desses tempos assume? Por outro lado, se, como esperamos, pudermos falar em representação de momento de referência também para tempos simples, que elemento desempenhará, nos tempos simples, o papel que Bertinetto atribui aos auxiliares nos tempos compostos, ou seja, que elemento será responsável pela denotação do momento de referência nos tempos simples, que não dispõem de um auxiliar?

\section{Conclusão}

Neste trabalho apresentei as reflexões que fiz sobre o trabalho de Wachowicz, que discute a questão do aspecto do auxiliar. Com base na proposta da autora de que os auxiliares ter, vir e estar são responsáveis pela abertura do 
intervalo do momento de referência para que os momentos de evento denotados pelo verbo principal da perífrase possam se distribuir, levantei questões sobre o sistema de traços que se apresentam nas perífrases e sobre a correção ou não de se representar o momento de referência também para os tempos simples, além de apenas para os tempos compostos, como sugere Bertinetto (1982). Vale dizer que as observações que faço pretendem, tão somente, contribuir para a discussão sobre a questão do aspecto do auxiliar, levantada, muito apropriadamente, por Wachowicz.

\section{Referências Bibliográficas}

BENVENISTE, E. As relações de tempo no verbo francês. In: BENVENISTE, E. Problemas de lingüística geral I. Campinas, SP: Pontes, 1988.

BERTINETTO, P. M. Intrinsic and extrinsic temporal reference: on restricting the notion of 'reference time'. Journal of Italian Linguistics, p. 71-108, 1982.

. On a frequent misunderstanding in the temporal-aspectual domain: the perfective-telic confusion. In: CECHETTO, C. et al. Semantic Interfaces: references, anaphora and aspect. Stanford: CSLI Publications, 2001.

CARDOSO, A.; PEREIRA, S. Contributos para o estudo da emergência do tempo composto em português. Revista da ABRALIN, v. 2, n. 2, p. 159-181, 2003.

FIORIN, J. L. As astúcias da enunciação. São Paulo: Ática, 2002.

JOHNSON, M. R. A unified temporal theory of tense and aspect. In: TEDESCHI, P. J. ZAENEN, A. (Ed.). Syntax and Semantics. New York: Academic Press, Inc, 1981. v. 14. p. 145-175.

MATTOS-e-SILVA, R. V. Estruturas trecentistas: elementos para uma gramática do português arcaico. Lisboa: Imprensa Nacional, 1989.

. O português arcaico: morfologia e sintaxe. São Paulo: Contexto, 2001. (Série: Repensando a língua portuguesa)

VENDLER, Z. Linguistics in Phylosophy. Ithaca/London: Cornell University Press, 1967.

WACHOWICZ, T. C. O aspecto do auxiliar. In: Encontro do GT em Teoria da Gramática da ANPOLL, Ouro Preto, 1 a 2/12/2005.

WACHOWICZ, T. C. O aspecto do auxiliar. Revista de Estudos da Linguagem, v. 14, n 2, p. 55-76, 2006. 